\title{
Bioadhesive HPMC Gel Containing Gelatin Nanoparticles for Intravaginal Delivery of Tenofovir
}

\author{
Sreejan Manna ${ }^{a^{*}}$, Uppadi Swathi Lakshmi ${ }^{a}$, Manasa Racharla ${ }^{a}$, Pratyusha Sinha ${ }^{\mathrm{b}}$, Lakshmi Kanta Kanthal ${ }^{\mathrm{a}}$, \\ S. P. N. Kumar ${ }^{\mathrm{a}}$ \\ ${ }^{a}$ Koringa College of Pharmacy, Korangi - 533 461, Tallarevu (M), E. G. Dt., Andhra Pradesh, India. \\ ${ }^{\mathrm{b}}$ Smt. B. N. B. Swaminarayan Pharmacy College, NH 8, Salvav - 396 191, Vapi, Valsad Dt., Gujarat, India.
}

\begin{tabular}{l} 
ARTICLE INFO \\
\hline Article history: \\
Received on: $16 / 06 / 2016$ \\
Revised on: $12 / 07 / 2016$ \\
Accepted on: $30 / 07 / 2016$ \\
Available online: $30 / 08 / 2016$ \\
\hline Key words: \\
Tenofovir, gelatin, \\
glutaraldehyde, bioadhesive, \\
HPMC K15M.
\end{tabular}

\begin{abstract}
The aim of the present study is to formulate tenofovir loaded gelatin nanoparticles by two step desolvation method for targeted release of drug by varying the concentration of polymer and cross-linking agent. Entrapment efficiency for all the formulations was found to be within $67.32 \pm 1.24 \%$ to $92.11 \pm 1.13 \%$. Average particle size of different tenofovir loaded gelatin nanoparticle formulations was found within the range of $294.9-445.3 \mathrm{~nm}$. In-vitro drug release study for glutaraldehyde cross linked gelatin nanoparticles were found between $67.09 \% \pm 1.423-82.41 \% \pm 1.874$ after $8 \mathrm{~h}$ of dissolution. F5 (850 mg gelatin, $0.2 \mathrm{ml}$ glutaraldehyde) was considered as the best formulation based on the entrapment efficiency and drug release from nanoparticle core. Kinetics study was performed for all the formulations and best fit model for drug release was determined depending on R squared values. HPMC K15M was used as a bioadhesive polymer as well as a gelling agent. Three different gel formulations were prepared by varying concentration of HPMC K15M and incorporated with the best formulation, F5. Membrane permeation and bio-adhesion study revealed F5B gel (5\% HPMC K15M) as an optimum formulation with suitable bioadhesive strength and membrane permeability.
\end{abstract}

\section{INTRODUCTION}

According to WHO and the Joint United Nation Program on HIV/AIDS (UNAIDS), HIV claimed more than 25 million lives worldwide since first recognised in December, 1981(WHO/EURO report.,1996; WHO/EM report., 1998). Since then, AIDS continues to be an opportunistic infection and a major threat to health globally (WHO., 1999; Espinoza et al., 2007). In spite of prevention strategies such as safe sex practice and spreading awareness on the same, the incidence of STDs have not succumbed (Gewirtzman et al., 2011). This scenario potentiates the need to combat the risk of STDs in near future. WHO recommended the class of new emerging anti-retrovirals can be widely used for pre-exposure prophylaxis (PrEP) of AIDS (Padian et al., 2008; Anthony et al., 2015). PrEP is the use of antiretroviral medications by HIV-negative persons to prevent

\footnotetext{
* Corresponding Author

Sreejan Manna, Koringa College of Pharmacy, Korangi - 533 461, Tallarevu (M), E. G. Dt., Andhra Pradesh, India.

Email:manna.sreejan@gmail.com
}

HIV infection upon high risked HIV exposure. Tenofovir is a nucleotide analogue reverse transcriptase inhibitor which has emerged as potential PrEP drug with a wide safety index. In spite of being an effective drug for children and adolescents (WHO, 2010), tenofovir suffers a range of disadvantages such as GI side effects, low permeability and low oral bioavailability (Peter et al., 2011). Topical delivery of microbicides is a useful alternative for prevention strategies of sexually transmitted diseases like HIV. Avoidance of first pass effect, increased area for drug penetration, less enzymatic activity and rich vascularisation has made vaginal tract an important site for drug administration (Bernkop and Hornof, 2003). As per a current research by U. Parikh et al., pig tail macaque monkeys treated with vaginally applied tenofovir before exposure to simian HIV (SHIV) remained free of infection after 20 challenges ( $\mathrm{p}<0.005$ versus control groups)(Parikh et al., 2009). Furthermore, CAPRISA 004 trial confirmed effectiveness of a $1 \%$ vaginal gel of tenofovir for the prevention of HIV infection in women. This double-blind, randomized controlled clinical trial claimed that tenofovir gel could prove to be a promising brick in the HIV prevention gap (Abdool et al., 2010). 
Gelatin nanoparticles (Jahanshahi et al., 2008) have earlier been used for effective delivery of DNA and proteins with a major advantage of its ease of cross-linking, nonpyrogenicity, less cellular toxicity and low antigenicity (Schwick and Heide., 1969). In the present research, tenofovir was incorporated into cross linked, biodegradable gelatin nanoparticles by double desolvation method (Kreuter et al., 2000).

The vaginal gel formulation of tenofovir will be particularly helpful in interfering with the sexual transmission of HIV in women. The mucoadhesive nature of the gel helps to retain the formulation for a longer period of time facilitating sustained release of the drug at site of action (Flynn, 1996), overcoming drug resistance and reduced toxicity (Brigger et al., 2002; Deverdiere et al., 1994).

\section{MATERIALS AND METHOD}

\section{Materials}

Tenofovir was received as a gift sample from Aurobindo Pharma, Hyderabad, India. Gelatin and HPMC K15M was received as a gift sample from Alembic Ltd, Vadodara, India. Glutaraldehyde was procured from Sigma Aldrich Chemicals Pvt. Ltd., Mumbai, India. The chemicals and reagents used were of analytical grades.

\section{Preparation of tenofovir nanoparticles by two step desolvation method}

Gelatin nanoparticles of tenofovir were prepared by two step desolvation method (Weber et al., 2000). Different concentrations of gelatin solution were prepared by dissolving required quantity of gelatin in $20 \mathrm{ml}$ of distilled water in a constant heating temperature. $20 \mathrm{ml}$ of acetone was added to the prepared gelatin solution for precipitating high molecular weight gelatin. The supernatant layer was discarded and high molecular weight gelatin was re-dissolved again by using $20 \mathrm{ml}$ of distilled water. The $\mathrm{pH}$ of the gelatin solution was adjusted to 5.6 with the help of $0.1 \mathrm{~N}$ sodium hydroxide solution.

Tenofovir was dispersed separately with tween 20 and then added drop-wise to the gelatin solution with continuous stirring. Glutaraldehyde was added in various concentrations to study the effect of cross-linking on particle size, drug entrapment and release of the drug from polymeric nanoparticles. Stirring was continued up to $8 \mathrm{~h}$ and then the prepared nanoparticles were separated by centrifugation at $2000 \mathrm{rpm}$. The nanoparticles were collected and washed with distilled water and then dried at $40^{\circ} \mathrm{C}$.

\section{Characterization of tenofovir nanoparticles Estimation of drug entrapment efficiency}

Accurately weighed $50 \mathrm{mg}$ of each nanoparticle formulations were taken and placed in $100 \mathrm{ml}$ of acetate buffer solution having $\mathrm{pH} 4.5$ was kept $24 \mathrm{~h}$ under constant stirring condition. After $24 \mathrm{~h}$, the solution was filtered through Whatman filter paper and the drug content in the filtrate was determined spectrophotometrically at $261 \mathrm{~nm}$ by using UV-VIS spectrophotometer (Elico Lab, SL 210).

\section{Fourier transformed infrared spectroscopy (FTIR)}

Drug- excipient compatibility study was carried out by the FTIR analysis of pure drug (tenofovir), pure polymer (gelatin) and nanoparticle formulation containing tenofovir using FTIR spectrometer (IRAffinity-1S,Shimadzu, Japan). Each sample grounded and mixed with $\mathrm{KBr}$ (Uvasol, Merck, KgaA, Germany). Pellets of the resulting mixture were prepared by using hydraulic press with an applied pressure of $100 \mathrm{Kg} / \mathrm{cm}^{2}$ for $15 \mathrm{~min}$. The pellets were then scanned from 4000 to $400 \mathrm{~cm}^{-1}$ with a mirror speed of $2 \mathrm{~mm} / \mathrm{sec}$.

\section{Determination of particle size and zeta potential}

The prepared tenofovir nanoparticles were dispersed in distilled water and sonicated for 5 minutes. The sonicated suspension was tested for particle size and zeta potential by using a light scattering particle size analyzer (Malvern Instruments Ltd., S1. No.-MAL 1040985).

\section{Scanning electron microscopy}

Tenofovir loaded gelatin nanoparticles were analyzed for surface morphology by field emission- scanning electron microscope (FE-SEM) (JEOL, JSM-6360, Japan). At first few samples were deposited on stub using one side of a double-sided adhesive dried carbon tape (NEM Tape, Nisshin Em. Co. Ltd. Tokyo, Japan) and then kept under saturated vapour of palladium to make them conductive. It was mounted on SEM instrument and the morphology of the nanoparticles was examined by secondary electro image (SEI) detector.

\section{In-vitro release study from tenofovir loaded gelatin nanoparticles}

In-vitro release of tenofovir from prepared gelatin nanoparticles was performed across the membrane of dialysis bag. The drug release study was performed in USP type II dissolution apparatus (Lab India D5 8000) containing $900 \mathrm{ml}$ of acetate buffer solution $\mathrm{pH} 4.5$. The temperature was maintained at $37.4 \pm 0.5^{\circ} \mathrm{C}$ under $50 \mathrm{rpm}$ speed. Accurately weighed quantity of $50 \mathrm{mg}$ nanoparticle formulation of tenofovir placed in dialysis bag (Cellophane membrane, Hi-media, India) containing $3 \mathrm{ml}$ of acetate buffer solution. Then the dialysis bag was tied on both ends and placed in dissolution apparatus. The dialysis bag acted as a donor compartment, while the dissolution vessel acted as receptor compartment. $5 \mathrm{ml}$ of aliquots was collected at regular intervals and replaced with fresh buffer solution to maintain sink condition throughout the experiment. The aliquots were filtered and diluted appropriately before determining the absorbance by using a UVVIS spectrophotometer (Elico Lab, SL 210) at $\lambda_{\max } 261 \mathrm{~nm}$.

\section{Release kinetics}

The drug release pattern from prepared gelatin nanoparticles of tenofovir were studied for various kinetic models like zero order, first order, Higuchi and Korsmeyer- Peppas model. 
Zero order kinetics: $Q_{t}-Q_{0}=K_{0} t$; Where, $\mathrm{Q}_{\mathrm{t}}$ is the amount of drug released after time $t, \mathrm{Q}_{0}$ is the initial concentration of the drug in solution; $\mathrm{K}_{0}$ is the zero order rate constant (Hadjiioannou et al., 1993).

First order kinetics: $\log Q_{t}=\log Q_{0}-\frac{K_{1} t}{2.303}$; Where, $Q_{\mathrm{t}}$ is the amount of drug released after time $t, Q_{0}$ is the initial concentration of the drug in solution; $\mathrm{K}_{1}$ is the first order rate constant (Bourne., 2002).

Higuchi model: $Q=K t^{0.5}$; Where, $\mathrm{Q}$ is the amount of drug released after time $\mathrm{t}$; and $\mathrm{K}$ is the rate constant (Higuchi., 1963).

Korsmeyer-Peppas model: $Q=K t^{n}$; Where, $\mathrm{Q}$ is the amount of drug released after time $t, K$ is the rate constant and $n$ is diffusional exponent for drug release.

Korsmeyer-Peppas model can also distinguish the exact release mechanism of drug. Depending on the $n$ value obtained from the experiment, the data were analyzed for various release mechanisms: Fickian release (diffusion controlled release), nonFickian release (anomalous transport) and case II transport (relaxation controlled release). In this context, $\mathrm{n} \leq 0.43$ indicates Fickian release, $0.43<\mathrm{n}<0.85$ indicates non-Fickian release, and $\mathrm{n} \geq 0.85$ symbolize a case II transport (Ritger and Peppas., 2002).

\section{Preparation of HPMC K15M gel containing 1\% tenofovir}

Intravaginal nanogel of tenofovir was prepared by using

HPMC K15M as a gel forming agent. Three different gel formulations F5A, F5B, F5C were prepared by dissolving different concentrations of HPMC K15M in $30 \mathrm{ml}$ of acetate buffer ( $\mathrm{pH} 4.0$ ) with continuous stirring by magnetic stirrer (Remi motors, India) at $300 \mathrm{rpm}$ to get a uniform clear dispersion. The resultant gels were kept undisturbed overnight for complete swelling (Ahmad et al., 2008). Then accurately weighed quantity of tenofovir nanoparticles equivalent to $100 \mathrm{mg}$ of tenofovir was mixed homogenously with the HPMC K15M solution. Finally $1 \%$ tenofovir nanogel was prepared by using glycerine as humectant, citric acid as penetration enhancer and triethanolamine as $\mathrm{pH}$ modifier.

Characterization of HPMC K15M gel containing tenofovir loaded gelatin nanoparticles Determination of $\mathrm{pH}$

The $\mathrm{pH}$ of the prepared nanogel formulations were determined by using a digital $\mathrm{pH}$ meter (Elico Lab, India) by dipping the glass electrode in to the gel system completely.

\section{Measurement of viscosity}

The viscosity of the prepared $1 \%$ tenofovir gel was determined by using Brookfield viscometer DV-III Ultra (Middleboro, USA) at $25 \pm 0.5^{\circ} \mathrm{C}$. Spindle number 6 was used to measure the viscosity at $10 \mathrm{rpm}$.

\section{Determination of spreadability}

Spreadability of the prepared gel was determined by placing $1 \mathrm{gm}$ of gel in the centre of a glass plate which was covered with another glass plate of same size $(20 " \times 20 ") .1000 \mathrm{~g}$ of weight was carefully placed on the upper glass plate for expelling air and uniform spreading of gel. After $1 \mathrm{~min}$, weight was removed and the spreading area of the gel between the glass plates was measured (Lardy et al., 2000; Garg et al., 2002).

\section{Determination of bioadhesive strength}

Bioadhesive property was determined using modified physical balance method (Harish et al., 2009). Chick ileum mucosa was used as biological membrane, which was fixed under one pan of the balance with the help of glue and was hydrated with acetate buffer $\mathrm{pH} 4.5$ maintained at $37+0.5^{\circ} \mathrm{C}$. Accurately weighed amount of $1 \mathrm{~g}$ of gel was stuck to the inverted beaker (250 ml) using glue and the height of the balance was adjusted to accommodate a glass container below the pan where membrane was glued. A preload of $20 \mathrm{~g}$ was applied in order to allow the formation of mucoadhesive joints. After a $3 \mathrm{~min}$ rest period, the preload was removed and gradually the weight was added to the other pan until the gel was detached from the mucosal surface (Ellaithy and El-Shaboury, 2002). The total weight required for the complete detachment of the gel was recorded. The mucoadhesive force expressed as the detachment stress in dynes $/ \mathrm{cm}^{2}$ was determined from the minimal weight that detached the mucosal tissue from surface of each formulation.

$$
\text { Mucoadhesive Strength }=\frac{\mathrm{mg}}{A}
$$

Where, $\mathrm{m}=$ Weight required for detachment in $\mathrm{gm}$, $\mathrm{g}=$ Acceleration due to gravity $\left(981 \mathrm{~cm} / \mathrm{s}^{2}\right)$,

$\mathrm{A}=$ Area of mucosa exposed.

\section{Membrane permeation study}

The membrane permeation study for the prepared tenofovir gels were carried out to measure the cumulative amount of drug permeating trough a biological membrane. Egg membrane was used as a biological membrane in this study.

\section{Preparation of the membrane}

The egg was kept in concentrated hydrochloric acid to dissolve the shell. Then by puncturing the membrane from one end, the contents were taken out. The membrane was then cleaned by using double distilled water. After thoroughly cleaning of membrane, it was kept in a petri dish containing acetate buffer $\mathrm{pH}$ 4.5 for overnight soaking.

\section{Permeation study by Franz diffusion cell}

The membrane permeation study was performed by using Franz diffusion cell which consist of two chambers- the donor compartment and receptor compartment. The egg membrane was mounted between the compartments by facing the outer side of the membrane towards the donor compartment. Acetate buffer $\mathrm{pH} 4.5$ was used as a receptor medium. The total set up was done over a magnetic stirrer with a maintained temperature of $37 \pm 0.5^{\circ} \mathrm{C}$. The 
donor compartment was filled with $1 \mathrm{gm}$ of nanogel formulation. At appropriate intervals, $2 \mathrm{ml}$ of receptor medium was withdrawn and replaced with equal volume of fresh medium. The amount of permeated drug through the membrane was analyzed by using a UV-VIS spectrophotometer (Elico Lab, SL 210) at $261 \mathrm{~nm}$ wavelength in reference with an appropriate blank buffer solution (Narendra et al., 2011).

\section{Accelerated stability study of prepared gels}

Accelerated stability test (Sanjay et al., 2012) was carried out for all the prepared gels at accelerated conditions of temperature and humidity $\left(40 \pm 2{ }^{\circ} \mathrm{C}\right.$ and $\left.75 \pm 5 \% \mathrm{RH}\right)$ for a period of 90 days. Samples were withdrawn at regular time interval (1, 2 and 3 month) and analyzed for appearance, $\mathrm{pH}$, drug content and compared with zero time samples as controls.

\section{RESULTS AND DISCUSSION}

\section{Drug entrapment efficiency}

The entrapment efficiency of tenofovir loaded gelatin nanoparticle formulations were found to be within the range of $67.32 \pm 1.24$ to $92.11 \pm 1.13$ as shown in Table 3 . F-5 was found to have the highest entrapment efficiency where as F-1 contains lowest amount of drug. From the drug entrapment result, we can also conclude that the increase in glutaraldehyde concentration is directly proportional to drug entrapment efficiency. This may attribute due to high degree of cross-linking brought about by glutaraldehyde.

\section{FTIR spectroscopy}

FTIR spectrum of tenofovir, gelatin and glutaraldehyde crosslinked nanoparticle formulation (F5) was shown in Fig. 1. Hydrogen bond formation is observed in formulation, which was detected by broadening of peak at 3200 to $3500 \mathrm{~cm}^{-1}$. FTIR spectrum of tenofovir shows peak at $1762.94 \mathrm{~cm}^{-1}$ for presence of carbonyl group $(\mathrm{C}=\mathrm{O})$ which can be observed in formulation $\left(1734.01 \mathrm{~cm}^{-1}\right)$. Peaks for $\mathrm{C}-\mathrm{C}$ stretching for aromatic ring, C-N stretching for aromatic amines, $\mathrm{C}-\mathrm{N}$ stretching for aliphatic amines, $\mathrm{C}-\mathrm{H}$ bending for alkenes, $\mathrm{C}-\mathrm{Cl}$ stretching for alkyl halides were observed at $1409.96 \mathrm{~cm}^{-1}, 1300.02 \mathrm{~cm}^{-1}, 1246.02 \mathrm{~cm}^{-1}, 952$ $\mathrm{cm}^{-1}$ and $746.45 \mathrm{~cm}^{-1}$ respectively. The FTIR spectrum of tenofovir loaded nanoparticles showed peaks at $1421.54 \mathrm{~cm}^{-1}, 1269.16 \mathrm{~cm}^{-1}$, $1186.22 \mathrm{~cm}^{-1}, 952.84 \mathrm{~cm}^{-1}$ and $788.89 \mathrm{~cm}^{-1}$ for C-C stretching for aromatic ring, C-N stretching for aromatic amines, $\mathrm{C}-\mathrm{N}$ stretching for aliphatic amines, $\mathrm{C}-\mathrm{H}$ bending for alkenes, $\mathrm{C}-\mathrm{Cl}$ stretching for alkyl halides respectively. The characteristic peaks appeared in the FTIR spectrum of tenofovir was also appeared in the spectrum of tenofovir loaded gelatin nanoparticles without any significant shifting of peaks, indicating absence of any chemical interaction during and after preparation.

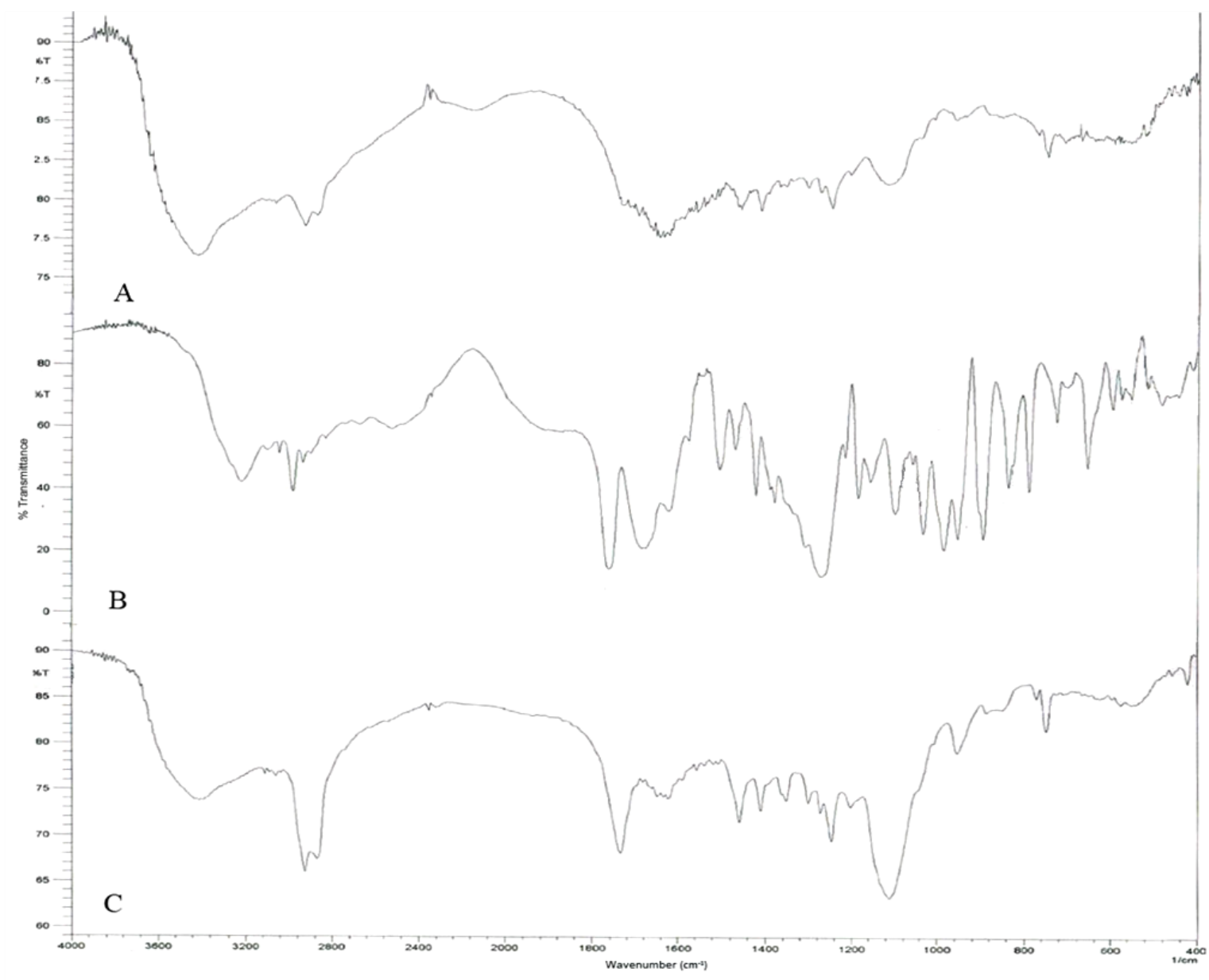

Fig. 1: FTIR spectrum of - A- pure tenofovir; B- Pure gelatin; C- tenofovir loaded nanoparticle formulation (F5) 
Table 1: Composition of various gelatin nanoparticle formulations.

\begin{tabular}{|c|c|c|c|c|c|c|c|}
\hline \multirow[b]{2}{*}{$\begin{array}{c}\text { Formulation } \\
\text { code }\end{array}$} & \multicolumn{6}{|c|}{ Composition } & \multirow{2}{*}{$\begin{array}{c}\text { Average particle } \\
\text { size } \\
(\mathbf{n m})\end{array}$} \\
\hline & $\begin{array}{c}\text { Tenofovir } \\
\text { (mg) }\end{array}$ & $\begin{array}{c}\text { Gelatin } \\
\text { (mg) }\end{array}$ & $\begin{array}{l}\text { Glutaraldehyde } \\
\text { (ml) }\end{array}$ & $\begin{array}{c}\text { Tween } 20 \\
(\mathrm{ml})\end{array}$ & $\begin{array}{l}\text { Acetone } \\
\text { (ml) }\end{array}$ & $\begin{array}{l}\text { Distilled water } \\
(\mathrm{ml})\end{array}$ & \\
\hline F1 & 100 & 500 & & 2.0 & 20 & 20 & 445.3 \\
\hline F2 & 100 & 600 & 0.1 & 2.0 & 20 & 20 & 326.2 \\
\hline F3 & 100 & 700 & 0.1 & 3.0 & 20 & 20 & 337.8 \\
\hline F4 & 100 & 800 & 0.1 & 3.0 & 20 & 20 & 380.6 \\
\hline F5 & 100 & 850 & 0.2 & 2.5 & 20 & 20 & 294.9 \\
\hline F6 & 100 & 850 & 0.3 & 2.5 & 20 & 20 & 308.2 \\
\hline
\end{tabular}

\begin{tabular}{|c|c|c|c|c|c|}
\hline & & & Size (r.nm): & $\%$ Intensity & Width $(\mathrm{r} \cdot \mathrm{nm})$ : \\
\hline Z-Average (r.nm): & 294.9 & Peak 1: & 189.5 & 100.0 & 35.71 \\
\hline Pdl: & 0.584 & Peak 2: & 0.000 & 0.0 & 0.000 \\
\hline Intercept: & 0.999 & Peak 3: & 0.000 & 0.0 & 0.000 \\
\hline
\end{tabular}

Result quality : Refer to quality report

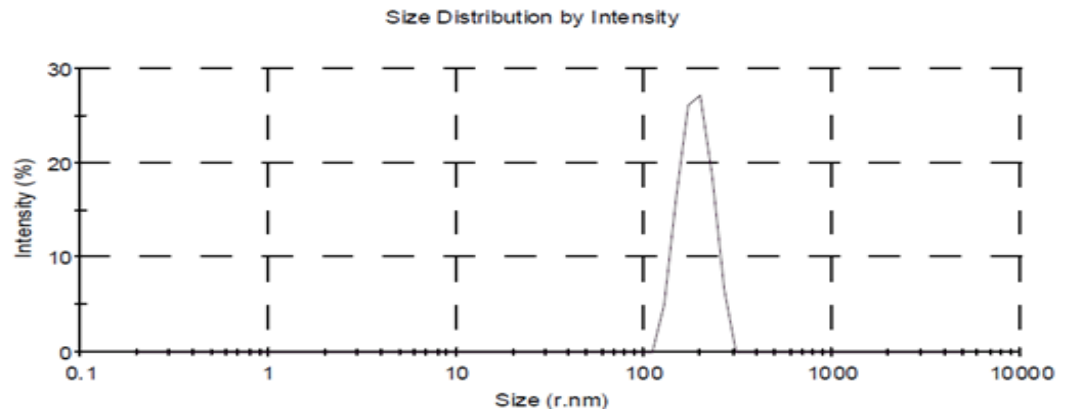

Fig. 2: Particle size distribution of tenofovir loaded gelatin nanoparticle formulation, F5.

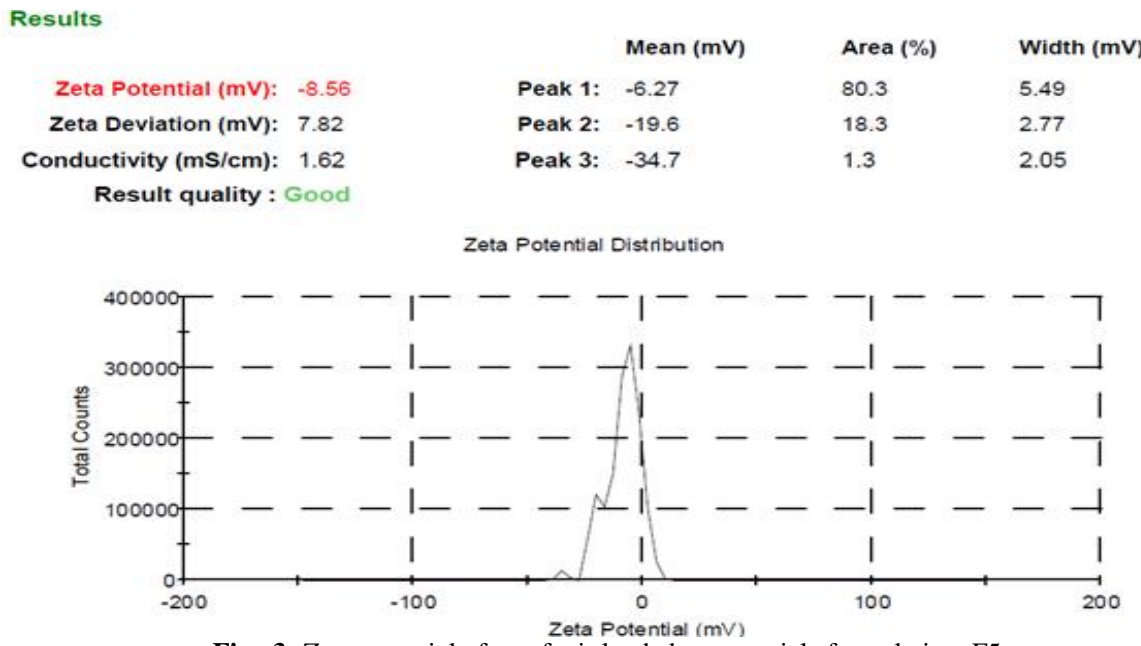

Fig. 3: Zeta potential of tenofovir loaded nanoparticle formulation, F5.

\section{Particle size and zeta potential}

Average particle size and particle size distribution of different tenofovir loaded gelatin nanoparticle formulations were found to be $294.9-445.3 \mathrm{~nm}$ as shown in Table 1. Among all the formulations, F5 was found to have smallest particle size of 294.9 $\mathrm{nm}$ and the particle size distribution was shown in Fig. 2. The average particle diameter was found to be lesser with increase in glutaraldehyde concentration. It is also observed that there was an increase in average particle diameter at higher concentration of gelatin which could be due to variation in degree of cross-linking. The higher concentration of cross-linker (glutaraldehyde) provides higher degree of cross-linking which results the decrease in average diameter of nanoparticles (Jana et al., 2013). The zeta potential of F5 measured by Malvern zeta sizer was fund to be $8.56 \mathrm{mv}$ with a zeta deviation of $7.82 \mathrm{mv}$ as shown in Fig. 3. The data indicates good stability of nanoparticle formulation in a colloidal dispersion due to electrical repulsion of the charged particles. 


\section{Surface morphology analysis}

The morphological analysis of prepared tenofovir nanoparticles were visualised by scanning electron microscope. Fig. 4 displays the SEM image of F5 formulation. The particles were found to be hemispherical in shape with smooth surfaces. No wrinkles or pores been observed on the surface.

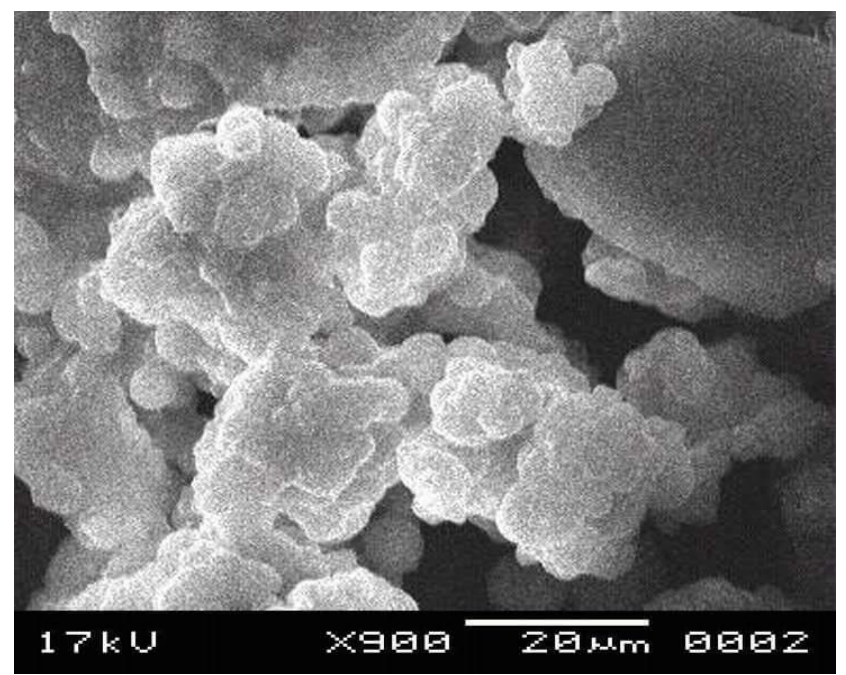

Fig. 4: Scanning electron micrograph of tenofovir loaded nanoparticles, F5.

Table 2: Composition of intra-vaginal nanogel of tenofovir.

\begin{tabular}{lccc}
\hline Ingredients & F5A & F5B & F5C \\
\hline Tenofovir loaded nanoparticles & $1 \%$ & $1 \%$ & $1 \%$ \\
equivalent to tenofovir & & & \\
HPMC K15M & $4 \%$ & $5 \%$ & $6 \%$ \\
Propyl paraben & $0.004 \mathrm{gm}$ & $0.004 \mathrm{gm}$ & $0.004 \mathrm{gm}$ \\
Methyl paraben & $0.072 \mathrm{gm}$ & $0.072 \mathrm{gm}$ & $0.072 \mathrm{gm}$ \\
Triethanolamine & $0.02 \mathrm{gm}$ & $0.02 \mathrm{gm}$ & $0.02 \mathrm{gm}$ \\
Glycerine & $2 \mathrm{ml}$ & $2 \mathrm{ml}$ & $2 \mathrm{ml}$ \\
Citric acid USP & $0.4 \mathrm{gm}$ & $0.4 \mathrm{gm}$ & $0.4 \mathrm{gm}$ \\
Purified water USP & $23.2 \mathrm{ml}$ & $22.8 \mathrm{ml}$ & $22.2 \mathrm{ml}$ \\
\hline
\end{tabular}

\section{In-vitro drug release from tenofovir loaded gelatin nanoparticles}

In-vitro release of tenofovir from the tenofovir loaded gelatin nanoparticles which are ionically cross-linked by glutaraldehyde was examined. The cumulative percentage release was calculated for all the formulation and was found to be sustained up to $8 \mathrm{~h}$. An initial burst release was observed for all the formulation which may be caused due to the drug present on the surface of the nanoparticles.

The cumulative percentage of drug released from glutaraldehyde cross-linked gelatin nanoparticles were found in between $69.45 \pm 1.171-84.09 \pm 1.423$ as shown in Fig. 5 .

After $8 \mathrm{~h}$ of time F-1 showed the highest amount of drug release which may happen because of loosely bound nanoparticle matrix (Sahana et al., 2010) due to absence of crosslinker. It is observed that the release of the drug from nanoparticle matrix is slower with increase in glutaraldehyde concentration which indicates the formation of firmly bound matrix with gradual increase in cross-linker concentration.

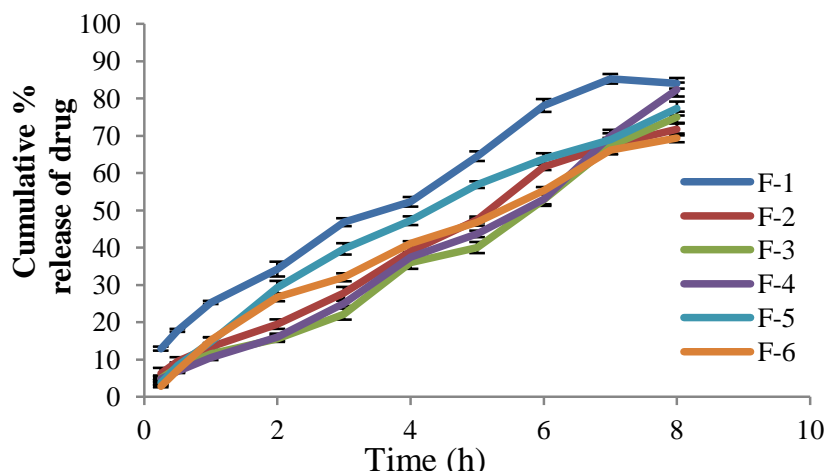

Fig. 5: In-vitro drug release from tenofovir loaded gelatin nanoparticles (mean \pm S. D.; $n=3$ ).

\section{Release kinetics}

In-vitro drug release study for prepared tenofovir nanoparticles were kinetically evaluated by using different mathematical models like zero order, first order, Higuchi and Korsmeyer- Peppas model and the results are shown in Table 3. Based on the accuracy of these mathematical models, the correlation coefficient $\left(\mathrm{R}^{2}\right)$ values were determined for each formulation. When the respective $\mathrm{R}^{2}$ values of tenofovir loaded gelatin nanoparticles are compared, it is been observed that $\mathrm{F} 1$ is following Korsmeyer- Peppas model of Fickian release, F2, F3, F4 are following zero order kinetics and F5 and F6 are following Higuchi model.

\section{pH of the prepared nanogel formulations}

In development of vaginal gel formulation, $\mathrm{pH}$ of the formulation plays an important role. Highly acidic or basic $\mathrm{pH}$ of vaginal gel formulation can alter the $\mathrm{pH}$ of surrounding environment, which may produce skin irritation on application of the gel. The $\mathrm{pH}$ of the prepared HPMC K15M gel containing tenofovir loaded gelatin nanoparticles were found to be 4.42, 4.45 and 4.47 for F5A, F5B and F5C respectively which are within the range of normal vaginal $\mathrm{pH}$.

\section{Viscosity}

The viscosity of prepared HPMC K15M gels containing tenofovir loaded gelatin nanoparticles were determined by using Brookfield viscometer. Formulation F5C (53454 $\pm 22 \mathrm{cps})$ was found more viscous in compare to formulation F5A (32398 \pm 19 cps) and F5B (37398 $\pm 15 \mathrm{cps})$ due to increase in HPMC K15M concentration.

\section{Spreadability}

The result for spreadability study of the prepared gel formulations was found to be satisfactory as shown in Table no 4. The high viscosity and bioadhesive property of the HPMC K15M could be responsible for decreasing the spreadability. From the data obtained, it can be clearly said that an increase in HPMC concentration is resulting in less spreadability of the prepared gel formulation. 
Table 3: Results of curve fitting of in-vitro release profile of tenofovir nanoparticles.

\begin{tabular}{|c|c|c|c|c|c|c|c|c|}
\hline \multirow[b]{2}{*}{ Sl. no } & \multirow[b]{2}{*}{ Formulation } & \multirow{2}{*}{$\begin{array}{c}\text { Zero order } \\
\qquad \mathbf{R}^{2}\end{array}$} & \multirow{2}{*}{$\begin{array}{c}\text { First order } \\
\qquad \mathbf{R}^{2}\end{array}$} & \multirow{2}{*}{$\underset{\mathbf{R}^{\mathbf{2}}}{\text { Higuchi }}$} & \multicolumn{2}{|c|}{ Koresmeyer-Peppas } & \multirow[b]{2}{*}{ Best fit model } & \multirow{2}{*}{$\begin{array}{c}\text { Drug entrapment } \\
\text { efficiency in \% } \\
(\text { mean } \pm \text { S.D.; } \mathbf{n}=3)\end{array}$} \\
\hline & & & & & $\mathbf{R}^{2}$ & $\mathbf{n}$ & & \\
\hline 1 & F1 & 0.874 & 0.958 & 0.977 & 0.988 & 0.418 & Koresmeyer-Peppas & $67.32 \pm 1.24$ \\
\hline 2 & $\mathrm{~F} 2$ & 0.982 & 0.971 & 0.952 & 0.978 & 0.113 & Zero order & $72.73 \pm 0.87$ \\
\hline 3 & F3 & 0.981 & 0.920 & 0.910 & 0.963 & 0.282 & Zero order & $80.24 \pm 1.34$ \\
\hline 4 & F4 & 0.982 & 0.882 & 0.912 & 0.972 & 0.389 & Zero order & $91.47 \pm 1.08$ \\
\hline 5 & F5 & 0.980 & 0.993 & 0.996 & 0.992 & 0.363 & Higuchi & $92.11 \pm 1.13$ \\
\hline 6 & F6 & 0.985 & 0.984 & 0.987 & 0.984 & 0.468 & Higuchi & $84.84 \pm 0.86$ \\
\hline
\end{tabular}

Table 4: Results of various evaluation parameters of tenofovir nanogel.

\begin{tabular}{ccccccc}
\hline $\begin{array}{c}\text { Formulation } \\
\text { code }\end{array}$ & pH & $\begin{array}{c}\text { Viscosity } \\
\text { (mean } \pm \text { S.D.; } \mathbf{n}=\mathbf{3})\end{array}$ & $\begin{array}{c}\text { Spreadability } \\
(\text { mean } \pm \text { S.D.; } \mathbf{n}=\mathbf{3})\end{array}$ & $\begin{array}{c}\text { Bioadhesive strength } \\
\text { (mean } \pm \text { S.D.; }=\mathbf{3})\end{array}$ & $\begin{array}{c}\text { Appearance } \\
\text { (after 3 months) }\end{array}$ & $\begin{array}{c}\text { Drug content after three } \\
\text { months } \\
(\mathbf{m e a n} \pm \text { S.D.; } \mathbf{n}=\mathbf{3})\end{array}$ \\
\hline F5A & 4.34 & $32398 \pm 19 \mathrm{cps}$ & $7.72 \pm 0.16$ & $5534 \pm 0.11$ & No change & $98.72 \% \pm 0.73$ \\
F5B & 4.38 & $37398 \pm 15 \mathrm{cps}$ & $7.37 \pm 0.13$ & $5643 \pm 0.13$ & No change \\
F5C & 4.40 & $53454 \pm 22 \mathrm{cps}$ & $6.86 \pm 0.08$ & $5672 \pm 0.14$ & No change & $98.64 \% \pm 0.35$ \\
\hline
\end{tabular}

\section{Bioadhesive strength}

Bioadhesive strength for all the prepared tenofovir nanogel formulation was carried out by modified physical balance method by using chick ileum mucosa as biological membrane. The bioadhesive strength of nanogel formulation was found within $5534 \pm 0.11,5643 \pm 0.13$ and $5672 \pm 0.14$ dynes $/ \mathrm{cm}^{2}$ for F5A, F5B and $\mathrm{F} 5 \mathrm{C}$ respectively as shown in Table 4. According to the requirement of the study, good bioadhesive strength was desired for better adherence and longer duration of action (Chatterjee et al., 2011). The above result indicated that the bioadhesive strength increased with proportional increase in HPMC K15M concentration in nanogel formulation.

\section{Membrane permeation study}

The HPMC K15M gels of tenofovir loaded gelatin nanoparticle formulation were evaluated for membrane permeation study by using egg membrane as a biological barrier. Fig. 6 displays controlled drug permeation from all the formulation was sustained over $10 \mathrm{~h}$.

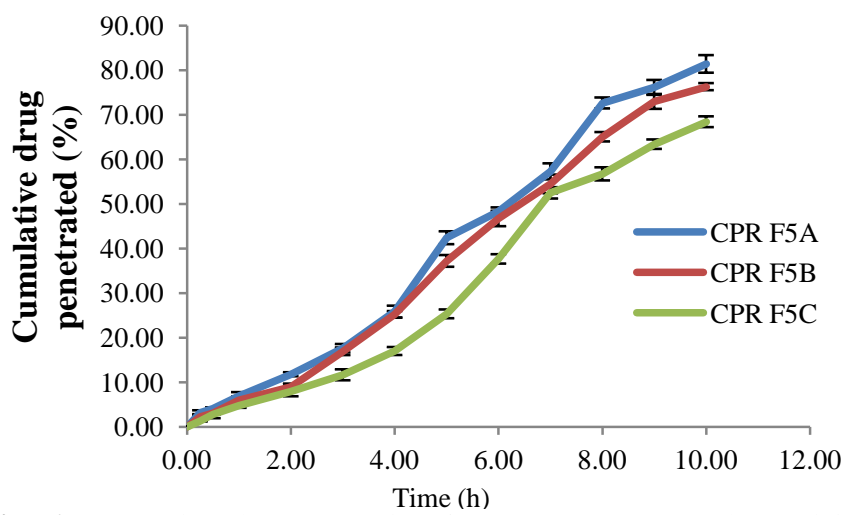

Fig. 6:Comparative drug permeation from HPMC K15M gel containing tenofovir loaded gelatin nanoparticles through egg membrane (mean \pm S. D.; $\mathrm{n}=3$ )

The penetration of tenofovir was significantly higher for F5A (81.36 \pm 1.97$)$ gel in compare with F5B (76.27 \pm 0.79$)$ and F5C $(68.40 \pm 1.20)$ gel formulation after $10 \mathrm{~h}$ of study.

\section{Accelerated stability study}

All the gel formulation were visually inspected in every week of first month and then at 1,2 and 3 month respectively. The clarity, transparency, and physical stability were compared with time zero gel formulation of each type. No significant changes were found in appearance of the gel formulations after 3 months. The $\mathrm{pH}$ of the prepared formulations F5A, F5B and F5C after 3 months was found to be $4.27,4.28$ and 4.36 respectively. After 3 months of exposure the drug content for F5A, F5B and F5C were resulted as $98.72 \% \pm 0.73,98.64 \% \pm 0.35$ and $98.83 \% \pm 0.28$ respectively as shown in Table 4 . The above data confirms that there are no significant changes in formulation after storing at ambient condition for 3 months and indicates a stable formulation.

\section{CONCLUSION}

Glutaraldehyde crosslinked gelatin nanoparticles were prepared successfully by two step desolvation method for sustained release of tenofovir. F5 was selected as best formulation based on the particle size, particle size distribution, drug entrapment efficiency and release pattern from polymeric matrix. The drug entrapment efficiency was found to be within the range of $67.32 \pm 1.24$ to $92.11 \pm 1.13$. The nanoparticles were found to be hemispherical in nature with an average particle size of 294.9 $445.3 \mathrm{~nm}$. Zeta potential for F5 (850 mg gelatin, $0.2 \mathrm{ml}$ glutaraldehyde) was found $-8.56 \mathrm{mv}$ which assures a stable colloidal dispersion of nanoparticles. The in-vitro dissolution study for nanoparticle formulation showed a sustained release of tenofovir over 8 h. 4\% (F5A), 5\% (F5B) and 6\% (F5C) HPMC $\mathrm{K} 15 \mathrm{M}$ gel was prepared by taking $1 \%$ equivalent weight of tenofovir from nanoparticle formulation F5. Bioadhesive strength analysis was carried out by modified physical balance method using chick ileum.

The results showed higher bioadhesion for $\mathrm{F} 5 \mathrm{C} \quad(6 \%$ HPMC K15M gel). Membrane permeation study was carried out by using egg membrane which reveals a higher permeation rate for F5A (4\% HPMC K15M) gel. By consolidating controlled drug permeation, viscosity, spreadability and bioadhesive strength, F5B 
(5\% HPMC K15M gel) was selected as optimum formulation with a standard bioadhesion and drug permeation profile.

\section{ACKNOWLEDGEMENTS}

This work was encouraged by the management of Koringa College of Pharmacy, Korangi, Andhra Pradesh, India.

\section{REFERENCES}

Abdool KQ, Abdool KSS, Frohlich JA, Grobler AC, Baxter C, Mansoor LE, Kharsany AB, Sibeko S, Mlisana KP, Omar Z, Gengiah, TN, Maarschalk S, Arulappan N, Mlotshwa M, Morris L, Taylor D. Effectiveness and safety of tenofovir gel, an antiretroviral microbicide, for the prevention of HIV infection in women. Science. 2010; 329, 1168 1174 .

Ahmad FJ, Alam MA, Khan ZI, Khar RK, Ali M. Development and in-vitro evaluation of an acid buffering bioadhesive vaginal gel for mixed vaginal infections. Acta Pharm. 2008; 58, 407-419.

Anthony SF, Hilary DM. Ending the HIV-AIDS pandemicfollow the science. N Engl J Med. 2015; 373, 2197-2199.

Bernkop AS, Hornof M. Intravaginal drug delivery systems design, challenges, and solutions. Am J Drug Del. 2003; 4, 241- 254.

Bourne DWA. 2002. Pharmacokinetics. In: Banker GS, Rhodes CT, ed. Mordern Pharmaceutics. New York: Marcel Dekker, 67-92.

Brigger I, Dubernet C, Couvreur P. Nanoparticles in cancer therapy and diagnosis. Adv Drug Del Rev.2002; 54, 631-651.

Chatterjee A, Bhowmik BB, Thakur YS. Formulation, In Vitro and In Vivo pharmacokinetics of Anti-HIV vaginal bioadhesive gel. J Young Pharmacists. 2011; 3, 83-89.

Deverdiere AC, Dubernet C, Nemati F, Poupon MF, Puisieux F, Couvreur P. Uptake of doxorubicin from loaded nanoparticles in multidrug-resistant leukemic murine cells. Cancer Chemother Pharmacol. 1994; 33, 504-508.

Ellaithy HM, El-Shaboury KMF. The development of Cutina lipogels and gel microemulsion for topical administration of fluconazole. AAPS PharmSciTech. 2002; 3, 77-85.

Espinoza L, Hall HI, Hardnett F, Selik RM, Ling Q, Lee LM. Characteristics of persons with heterosexually acquired HIV infection, United States 1999-2004. Am J Publ Health. 2007; 97, 144-149.

Flynn GL. 1996. Cutaneous and Transdermal Delivery: Processes and systems of Delivery. In: Banker GS, Rhodes CT, ed Modern Pharmaceutics. New York: Marcel Dekker, 193-241.

Garg A, Aggarwal D, Garg S, Singla AK. Spreading of semisolid formulations: an update. Pharmaceutical Technology. 2002; 26(9):84-105.

Gewirtzman A, Bobrick L, Conner K, Tyring SK. 2011. Epidemiology of sexually transmitted infections. In: Gross G, Tyring SK, ed. Sexually transmitted infections and sexually transmitted diseases. Verlag Berlin Heidelberg: Springer, 13-34.

Hadjiioannou TP, Christian GD, Koupparis MA, Macheras PE. 1993. Quantitative Calculations in Pharmaceutical Practice and Research. New York: VCH Publishers Inc. 345-348.

Higuchi T. Mechanism of sustained action medication. Theoritical analysis of rate of release of solid drugs dispersed in solid matrices. J Pharm Sci. 1963; 52, 1145-1149.

Jahanshahi M, Sanati MH, Babaei Z. Optimization of parameters for the fabrication of gelatin nanoparticles by the Taguchi robust design method. J Appl Stat. 2008; 35, 1345-1353.

Jana S, Manna S, Nayak AK, Sen KK, Basu SK. Carbopol gel containing chitosan- egg albumin nanoparticles for transdermal aceclofenac delivery. Colloids and Surf. B: Biointerfaces. 2014;114, 3644.

Kreuter J, Coester CJ, Langer K, Briesen VH. Gelatin nanoparticles by two step desolvation- a new preparation method, surface modifications and cell uptake. J Microencaps. 2000; 17, 187-193.
Lardy F, Vennat B, Pouget MP, Pourrat A. Functionalization of hydrocolloids: principal component analysis applied to the study of correlations between parameters describing the consistency of hydrogels. Drug Development and Industrial Pharmacy. 2000; 26(7): 715-721.

Harish NM, Narayana RC, Mohammed GA, Prabhakara P, Singh AK, Subrahmanyam EVS. Formulation and in-vitro evaluation of in situ gels containing secnidazole for vaginitis. Yakugaku Zasshi. 2009; 129, 569-574.

Narendra C, Prakash KT. Aceclofenac nanoemulsiosn for transdermal delivery: stability and in-vitro evaluation. Asian J Pharm Life Sci. 2011; 1, 354-369.

Padian NS, Buve A, Balkus J, Serwadda D, Cates WJr. Biomedical interventions to prevent HIV infection: evidence, challenges and way forward. Lancet. 2008; 372, 585-599.

Parikh UM, Charles D, Sunita S, Milan-er C, Hongwei J, Amy M, Chou-Pong P, Debra LH, Patricia G, James S, Ellen K, Gerardo GLJ, Francis JN, Ron O, Thomas F, Walid H. Complete protection from repeated vaginal simian-human immunodeficiency virus exposures in macaques by a topical gel containing tenofovir alone or with emtricitabine. J Virol. 2009; 83, 10358-10365.

Peter LA, Jennifer JK, Edward MG, Joseph ER, Amie M, Robert MG. Pharmacological considerations for tenofovir and emtricitabine to prevent HIV infection. J Antimicrob Chemother. 2011; $66,240-250$

Ritger PL, Peppas NA. A simple equation for description of solute release I. Fickian and non-Fickian release from non-swellable devices in the form of slabs, spheres, cylinders or discs. J Control Release. 1987; 5, 23-36.

Sahana B, Santra K, Basu S, Mukherjee B. Development of biodegradable polymer based tamoxifen citrate loaded nanoparticles and effect of some manufacturing process parameters on them: a physicochemical and in-vitro evaluation. Int J Nanomedicine. 2010; 5 , $621-630$

Sanjay B, Dinesh S, Neha S. Stability testing of pharmaceutical products. J App Pharm Sci. 2012; 02. 129-138.

Schwick HG, Heide K. Immunochemistry and immunology of collagen and gelatin, Bibl Haematol. 1969; 33.111-125.

Weber C, Coester C, Kreuter J, Langer K. Desolvation process and surface characterization of protein nanoparticles. Int J Pharm. 2000; 194, 91-102.

World Health Organization. 1996. WHO/EURO: Epidemic of sexually transmitted diseases in Eastern Europe. Report on a WHO meeting, Copenhagen, Denmark.

Available at: WWW.who.int/HIV_AIDS [Accessed 22 August 2015].

World Health Organization. 1998. WHO/EM: Report on the intercountry workshop on STD prevalence study, Amman, Jordan, 12-15 Oct 1998.

Available at: http://www.springer.com/978-3-642-14662-6 [Accessed 21 July 2015].

World Health Organization. 1999. STI/HIV status and trends of STI, HIV/AIDS at the end of the millennium. Western Pacific Region. Available at: www.who.org.ph [Accessed 12 August 2015].

World Health Organization. 2010. Antiretroviral therapy for HIV infection in adults and

adolescents: recommendations for a public health approach 2010 revision

Available at: www.who.int/hiv [Accessed 16 august 2015].

How to cite this article:

Manna S, Lakshmi US, Racharla M, Sinha P, Kanthal LK, Kumar SPN. Bioadhesive Hpmc Gel Containing Gelatin Nanoparticles for Intravaginal Delivery of Tenofovir. J App Pharm Sci, 2016; 6 (08): 022-029. 